\title{
Acid Corrosion Inhibition of Steel by Lamotrigine
}

\author{
B. S. Shylesha, ${ }^{1}$ T. V. Venkatesha, ${ }^{1}$ B. M. Praveen, ${ }^{2}$ and S. E. Nataraja ${ }^{1}$ \\ ${ }^{1}$ Department of Chemistry, School of Chemical Sciences, Kuvempu University, Karnataka 577 451, India \\ ${ }^{2}$ Department of Chemistry, Srinivas School of Engineering, Mukka, Mangalore 575 021, India
}

Correspondence should be addressed to T. V. Venkatesha, drtvvenkatesha@yahoo.co.uk

Received 27 August 2012; Accepted 13 September 2012

Academic Editors: G. Bereket, C. Gu, C.-H. Hsu, I. Obot, and E. Stupnisek-Lisac

Copyright ( 2012 B. S. Shylesha et al. This is an open access article distributed under the Creative Commons Attribution License, which permits unrestricted use, distribution, and reproduction in any medium, provided the original work is properly cited.

\begin{abstract}
Corrosion inhibition effect of lamotrigine on steel in $1.0 \mathrm{M} \mathrm{HCl}$ and $0.5 \mathrm{M} \mathrm{H}_{2} \mathrm{SO}_{4}$ was studied by techniques like weight loss, polarisation, and electrochemical impedance spectroscopy. Results indicated that lamotrigine is more competent in $\mathrm{HCl}$ than in $\mathrm{H}_{2} \mathrm{SO}_{4}$ and is justified by scanning electron micrographs. Protection efficiency increased with the concentration of inhibitor and decreased with temperature. Adsorption study revealed the comprehensive adsorption of lamotrigine molecules on steel surface.
\end{abstract}

\section{Introduction}

$\mathrm{HCl}$ and $\mathrm{H}_{2} \mathrm{SO}_{4}$ acids are widely used in processes like acid pickling, acid cleaning, acid descaling, and oil-well acidizing $[1,2]$, where the intention is to remove surface scales and deposits keeping the base metal intact. But acids, after the removal of scales and deposits, invariably attack the precious metal leading to deleterious consequences of acid corrosion. Use of inhibitors is the most practical method to combat this. Inhibitors are organic molecules which possess $\pi$-electrons, hetero atoms like nitrogen, sulphur, and oxygen $[3,4]$. These inhibitors generally act by adsorbing on the metal surface forming a thin protective film. In acid media, electron-rich center gets protonated to become cation, electrostatically binds to cathodic sites of metal thereby hinders cathodic reaction. Electron-rich spots of unprotonated molecule finds anodic reactive sites thus reduce anodic reaction. Thus, a heterocyclic organic molecule comprehensively acts. Recently, considerable amount of effort has been devoted to develop novel and efficient corrosion inhibitors. It is found that molecules containing both $\mathrm{N}$ and $\mathrm{S}$ can claim excellent inhibition compared with those containing only $\mathrm{N}$ or $\mathrm{S}[5,6]$. bis thiadiazole derivatives [7], thiosemicarbazide derivatives [8], Benzimidazole derivatives [9], and purines [10] have been verified to be efficient inhibitors for steel.

Generally acid pickling is carried out at high temperature $[11,12]$. In that case efficiency of the inhibitor generally goes down. Hence, it is important to find inhibitor which is fair at elevated temperatures. The study by Tang et al.
[13], Singh and Quraishi [7] showed that thiadiazoles retain inhibition efficiency up to $45^{\circ} \mathrm{C}$, bis-thiadiazoles up to $65^{\circ} \mathrm{C}$, respectively, and was attributed to chemisorption of inhibitor molecule on steel surface. Oguzie et al. argue that inhibitors containing sulphur heteroatom favor chemisorption whereas nitrogen favour physisorption, on the surface of steel, in acidic media [14].

This made us choose lamotrigine which has potential characters to perform well at elevated temperature. It has five nitrogen, two chlorine atoms, and two aromatic rings. These heteroatoms and $\pi$ electrons could be active centres for adsorption [15]. Lamotrigine being a small molecule, ease electronic interactions of inhibitor molecule with steel and impede steric effects [16, 17]. Moreover, lamotrigine has a fairly planar in-structure which facilitates it's adsorption on the metal surface $[18,19]$.

Present study was intended to ascertain the ability of lamotrigine to protect steel at different temperatures in $\mathrm{HCl}$ and $\mathrm{H}_{2} \mathrm{SO}_{4}$. Further to check the concordance in results by weight loss, Tafel and EIS techniques. Adsorption and thermodynamic factors were to be assessed to establish mechanism of adsorption. Scanning electron microscopic (SEM) images were to be referred to confirm the findings.

\section{Experimental}

2.1. Materials. Steel coupons having compositions $0.04 \%$ C, $0.35 \% \mathrm{Mn}, 0.022 \% \mathrm{P}, 0.036 \% \mathrm{~S}$, and the rest being $\mathrm{Fe}$ 
<smiles>Nc1nnc(-c2cccc(Cl)c2Cl)c(N)n1</smiles>

(a)

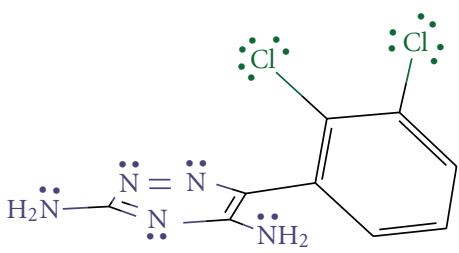

(b)
FIgURE 1: (a) 2D and (b) 3D Structure of Lamotrigine.

(99.55\%) were used for all experiments. Coupons of dimension $4 \mathrm{~cm} \times 2.5 \mathrm{~cm} \times 0.05 \mathrm{~cm}$ were used for mass loss method and coupons with an exposed area of $1 \mathrm{~cm}^{2}$ (rest is covered with araldite resin) with $2.5 \mathrm{~cm}$ long stem were used for polarization and EIS methods. All coupons were abraded by using emery papers (grade no.: 220, 400, 600, 800, and 1200), washed thoroughly with distilled water, degreased with acetone, and dried at room temperature. The corrosive media $1.0 \mathrm{M} \mathrm{HCl}$ solutions were prepared using AR grade $\mathrm{HCl}$ and double distilled water.

Lamotrigine, also known as Lamictal (IUPAC name: 6(2,3-dichlorophenyl)-1,2,4-triazine-3,5-diamine), is an anticonvulsant drug used in the treatment of epilepsy and bipolar disorder. It is also used as an adjunct in treating depression, though this is considered off-label usage [20]. The structures of lamotrigine are presented in Figure 1.

\subsection{Methods}

2.2.1. Weight Loss Measurements. Weight loss measurements were performed by immersing steel specimen in glass beaker containing $100 \mathrm{~cm}^{3}$ of corrosive media $(1.0 \mathrm{M} \mathrm{HCl}$ and $0.5 \mathrm{M} \mathrm{H}_{2} \mathrm{SO}_{4}$ ) without and with different concentrations of inhibitor. After an immersion period of $4 \mathrm{~h}$, specimen was taken out and washed well with distilled water, dried, weighed accurately using digital balance (accuracy: $\pm 0.1 \mathrm{mg}$, model no.: AA-2200, manufactured by Anamed Instruments Pvt. Limited, MIDC, Navi Mumbai 400706, India). To assess the effect of temperature on the inhibition efficiency of lamotrigine, experiments were carried out at $30,40,50$, and $60^{\circ} \mathrm{C}$. A digital thermostat $\left( \pm 0.5^{\circ} \mathrm{C}\right.$ accuracy $)$ was used for maintaining temperature. All corrosion experiments were carried out in aerated as well as static condition. Each measurement was repeated thrice for reproducibility, and an average value was reported.

2.2.2. Electrochemical Measurements. The Electrochemical measurements were carried out in CHI 660C electrochemical analyzer (manufactured by CH Instruments, Austin, USA) at $30^{\circ} \mathrm{C}$. The cell consists of three electrodes, namely, the working electrode (steel), counter electrode (platinum), and reference electrode (SCE). An immersion time of 30 minutes was given to allow the stabilization of the open circuit potential (OCP) potential. Each experiment was repeated for three times and an average value was reported. All reported potentials were with respect to SCE. For Tafel measurements,
TABLE 1: Corrosion parameters obtained from weight loss measurements for steel in $1.0 \mathrm{M} \mathrm{HCl}$ and $0.5 \mathrm{M} \mathrm{H}_{2} \mathrm{SO}_{4}$ in presence of various concentrations of lamotrigine.

\begin{tabular}{lccccc}
\hline $\begin{array}{l}\text { Corrosive } \\
\text { medium }\end{array}$ & $\begin{array}{c}\text { Inhibitor } \\
\text { concentration } \\
\mathrm{mM}\end{array}$ & \multicolumn{4}{c}{$\% \eta_{w}$ at different temperature } \\
& Blank & - & - & - & - \\
& 0.5 & 74.8 & 65.3 & 45.0 & 34.7 \\
$\mathrm{HCl}$ & 1.0 & 92.2 & 87.1 & 75.4 & 63.2 \\
& 2.5 & 95.5 & 92.0 & 86.0 & 80.0 \\
& 5.0 & 96.1 & 94.2 & 89.2 & 85.5 \\
\hline \multirow{4}{*}{} & 0.5 & 66.8 & 57.8 & 47.6 & 34.0 \\
$\mathrm{H}_{2} \mathrm{SO}_{4}$ & 1.0 & 80.1 & 71.4 & 65.0 & 54.7 \\
& 2.5 & 89.4 & 86.3 & 81.0 & 76.5 \\
& 5.0 & 93.0 & 91.8 & 88.0 & 83.6 \\
\hline
\end{tabular}

potential-current curves were scanned from $-0.2 \mathrm{~V}$ to $+0.2 \mathrm{~V}$ with respect to open circuit potential (OCP) at a constant sweep rate of $0.01 \mathrm{~V} \mathrm{sec}^{-1}$. Corrosion parameters such as corrosion potential $\left(E_{\text {corr }}\right)$, corrosion current $\left(I_{\text {corr }}\right)$, cathodic Tafel slope $\left(\beta_{\mathrm{c}}\right)$, and anodic Tafel slope $\left(\beta_{\mathrm{a}}\right)$ were calculated from the software installed in the instrument.

Impedance measurements were carried out by using $\mathrm{AC}$ signal with amplitude of $5 \mathrm{mV}$ at $\mathrm{OCP}$ in the frequency range of $100 \mathrm{KHz}$ to $10 \mathrm{mHz}$. The impedance data were fitted to most appropriate equivalent circuit by using ZSimp Win 3.21 software. The impedance parameters were obtained from Nyquist plots.

2.2.3. Surface Morphology Studies. Scanning electron micrographs of steel surface immersed in $1.0 \mathrm{MHCl}$ and $0.5 \mathrm{M} \mathrm{H}_{2} \mathrm{SO}_{4}$ containing $2.5 \mathrm{mM}$ lamotrigine, at $30^{\circ} \mathrm{C}$, were taken using scanning electron microscope (JEOL, JSM 6400).

\section{Results and Discussion}

3.1. Mass Loss Studies. The values of percentage protection efficiency $\left(\% \eta_{w}\right)$ obtained from weight loss experiment for the corrosion of steel in $1.0 \mathrm{M} \mathrm{HCl}$ and $0.5 \mathrm{M} \mathrm{H}_{2} \mathrm{SO}_{4}$ in presence of different concentration of lamotrigine are given in Table 1. The $\% \eta_{w}$ was calculated from the following relationship:

$$
\% \eta_{w}=\frac{W^{\circ}-W}{W^{\circ}} \times 100,
$$

where $W^{\circ}$ and $W$ are weight loss of steel in absence and presence of inhibitor.

3.1.1. Effect of Inhibitor Concentration. The variation of $\% \eta_{w}$ with concentration of lamotrigine, at $30^{\circ} \mathrm{C}$ is shown in Figure 2. It is evident from figure that lamotrigine has remarkable protection ability, both in $\mathrm{HCl}$ and $\mathrm{H}_{2} \mathrm{SO}_{4}$ media. It showed appreciable raise in $\% \eta_{w}$ with concentration upto $2.5 \mathrm{mM}$ for both $\mathrm{HCl}$ and $\mathrm{H}_{2} \mathrm{SO}_{4}$, thereafter, a marginal rise. At any selected temperature, in $\mathrm{HCl}$ or in 
TABle 2: Polarisation and impedance parameters for steel in $1.0 \mathrm{MHCl}$ and $0.5 \mathrm{M} \mathrm{H}_{2} \mathrm{SO}_{4}$ in presence of different concentration of lamotrigine.

\begin{tabular}{|c|c|c|c|c|c|c|c|c|c|}
\hline \multirow[b]{2}{*}{$\begin{array}{l}\text { Corrosive } \\
\text { media }\end{array}$} & \multicolumn{6}{|c|}{ Polarisation } & \multicolumn{3}{|c|}{ EIS } \\
\hline & $\begin{array}{c}\text { Inhibitor } \\
\text { concentration } \\
(\mathrm{mM})\end{array}$ & $\begin{array}{c}E_{\text {corr versus }} \\
\text { SCE } \\
(\mathrm{mV})\end{array}$ & $\begin{array}{c}I_{\text {corr }} \\
\left(\mu \mathrm{A} \mathrm{cm}^{-2}\right)\end{array}$ & $\begin{array}{c}\beta_{\mathrm{c}} \\
\left(\mathrm{mVV} \operatorname{dec}^{-1}\right)\end{array}$ & $\beta_{\mathrm{a}}\left(\mathrm{mV} \operatorname{dec}^{-1}\right)$ & $\% \eta_{p}$ & $\left(R_{p} \Omega \mathrm{cm}^{2}\right)$ & $\begin{array}{c}C_{\mathrm{dl}} \\
\left(\mu \mathrm{F} \mathrm{cm}^{-2}\right)\end{array}$ & $\% \eta_{z}$ \\
\hline \multirow{5}{*}{$\mathrm{HCl}$} & Blank & -0.484 & 170.0 & 126 & 86 & - & 112 & 62 & - \\
\hline & 0.5 & -0.460 & 43.2 & 112 & 76 & 74.5 & 418 & 27 & 73.2 \\
\hline & 1.0 & -0.469 & 11.4 & 102 & 151 & 93.2 & 1670 & 12 & 93.1 \\
\hline & 2.5 & -0.467 & 7.0 & 112 & 142 & 95.8 & 2941 & 8.8 & 96.2 \\
\hline & 5.0 & -0.460 & 5.1 & 112 & 107 & 97.0 & 3350 & 9.9 & 96.6 \\
\hline \multirow{5}{*}{$\mathrm{H}_{2} \mathrm{SO}_{4}$} & Blank & -0.489 & 155.6 & 123 & 88 & - & 72 & 71 & - \\
\hline & 0.5 & -0.480 & 49.2 & 115 & 77 & 68.3 & 222 & 56 & 67.5 \\
\hline & 1.0 & -0.478 & 30.4 & 94 & 65 & 80.4 & 590 & 22 & 87.5 \\
\hline & 2.5 & -0.459 & 20.3 & 114 & 134 & 86.9 & 1112 & 16 & 93.5 \\
\hline & 5.0 & -0.463 & 9.8 & 110 & 116 & 93.7 & 1602 & 10 & 95.5 \\
\hline
\end{tabular}

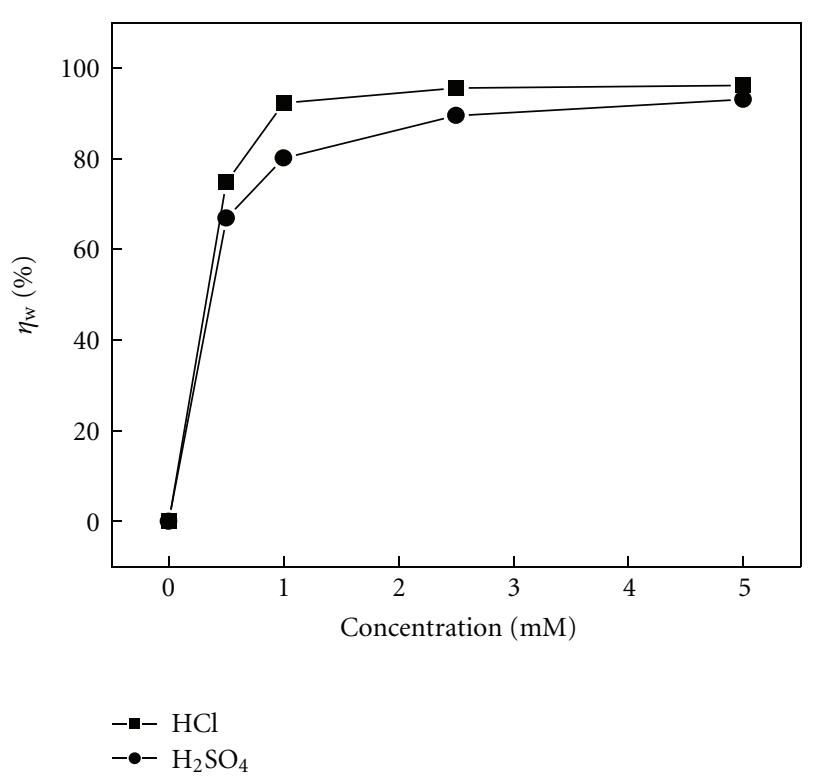

FIGURE 2: Variation of inhibition efficiency with inhibitor concentration, at $30^{\circ} \mathrm{C}$.

$\mathrm{H}_{2} \mathrm{SO}_{4}, \% \eta_{w}$ increased with inhibitor concentration which suggests magnitude of adsorption and surface coverage by inhibitor increases with concentration of inhibitor [21].

3.1.2. Effect of Temperature. Variation of $\% \eta_{w}$ with temperature is shown in Figure 3 which indicated that $\% \eta_{w}$, for both acids, decreased with the increase of temperature. This suggests desorption of previously adsorbed inhibitor molecules, from the steel surface, at elevated temperature indicating physical adsorption of inhibitor molecules [22, 23]. At any temperature, $\% \eta_{w}$ stands in the order $\mathrm{HCl}>$ $\mathrm{H}_{2} \mathrm{SO}_{4}$.
3.2. Polarization Studies. The polarization behavior of steel immersed in $1.0 \mathrm{M} \mathrm{HCl}$ and $0.5 \mathrm{M} \mathrm{H}_{2} \mathrm{SO}_{4}$ at $30^{\circ} \mathrm{C}$ in absence and presence of different concentration of lamotrigine is shown in Figure 4. Electrochemical parameters like corrosion potential $\left(E_{\text {corr }}\right)$, corrosion current density $\left(I_{\text {corr }}\right)$, cathodic Tafel slope $\left(\beta_{\mathrm{c}}\right)$, anodic Tafel slope $\left(\beta_{\mathrm{a}}\right)$, and percentage inhibition efficiency according to polarisation studies $\left(\% \eta_{p}\right)$ are listed in Table 2 . The $\% \eta_{p}$ was calculated from following relation:

$$
\% \eta_{p}=\frac{I_{\text {corr }}^{\circ}-I_{\text {corr }}}{I_{\text {corr }}^{\circ}} \times 100,
$$

where $I_{\text {corr }}^{\circ}$ and $I_{\text {corr }}$ are corrosion current densities in absence and presence of inhibitor, respectively. Results mainly point out the following: (a) $I_{\text {corr }}$ decreased with increase in concentration of inhibitor in the order $\mathrm{HCl}<\mathrm{H}_{2} \mathrm{SO}_{4}$ which reiterates lamotrigine is more effectual in $\mathrm{HCl}$. (b) $E_{\text {corr }}$ value was shifted towards less negative (noble) potential. It has been reported that [24] a compound can be classified as an anodic or a cathodic-type inhibitor on the basis of shift in $E_{\text {corr }}$ value. If displacement in $E_{\text {corr }}$ is greater than $85 \mathrm{mV}$, towards anode or cathode with reference to blank, then an inhibitor is categorized as either anodic or cathodic type inhibitor. Otherwise inhibitor is treated as mixed type. In our study, maximum displacement in $E_{\text {corr }}$ value was around $65 \mathrm{mV}$ indicating lamotrigine is a mixed type inhibitor, in both acids. (c) $\beta_{\mathrm{c}}$ and $\beta_{\mathrm{a}}$ values have changed with respect to inhibitor free solution, for both acids which reiterate that lamotrigine is mixed type inhibitor. Obtained $\% \eta_{p}$ values are in agreement with $\% \eta_{w}$ values.

3.3. EIS Studies. Electrochemical impedance spectra for steel in $1.0 \mathrm{M} \mathrm{HCl}$ and $0.5 \mathrm{M} \mathrm{H}_{2} \mathrm{SO}_{4}$ without and with different concentration of lamotrigine inhibitor at $30^{\circ} \mathrm{C}$ are presented as Nyquist plot in Figure 5. The diameter of semicircle increased with inhibitor concentration and is significant in $\mathrm{HCl}$, reflects the effectiveness of inhibitor [25]. An equivalent 


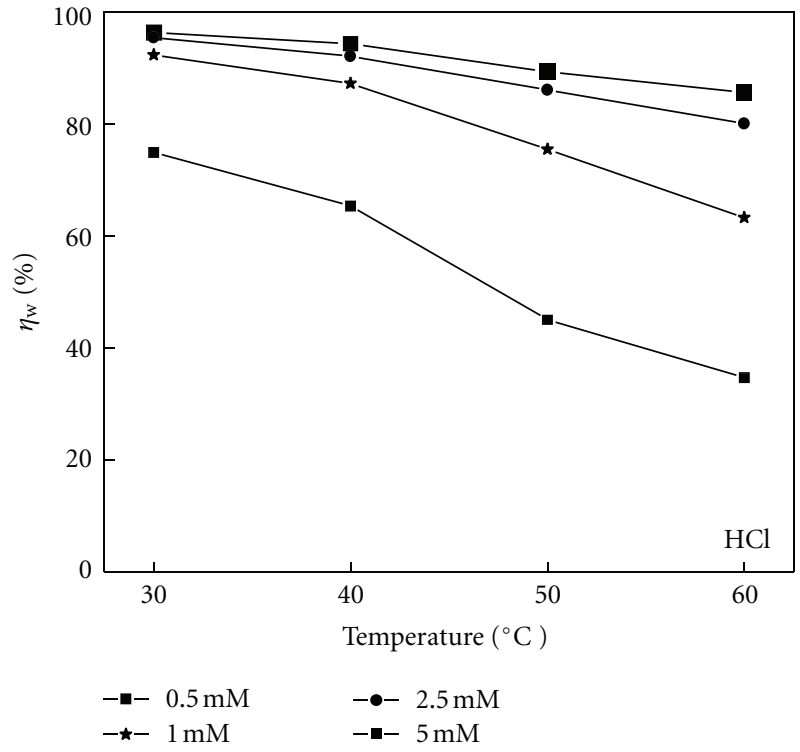

(a)

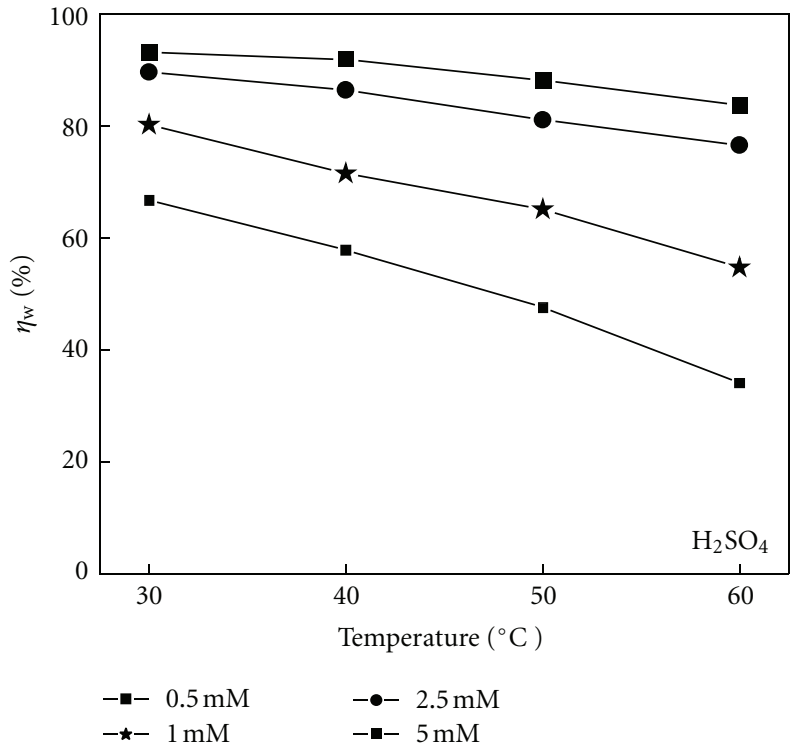

(b)

FIGURE 3: Variation of $\% \eta_{w}$ with temperature for steel in $1.0 \mathrm{M} \mathrm{HCl}$ and $0.5 \mathrm{M} \mathrm{H}_{2} \mathrm{SO}_{4}$ in presence of different concentration of inhibitor.

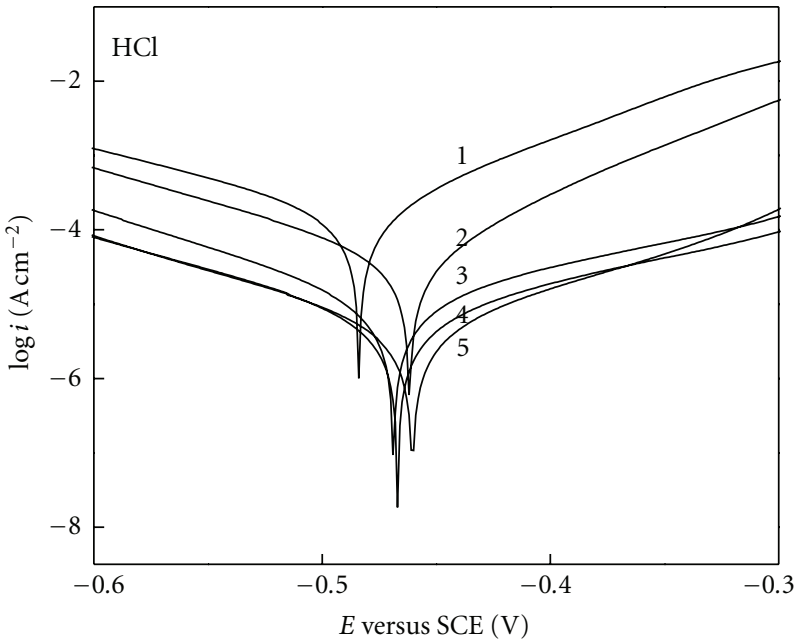
1: Blank
2: $0.5 \mathrm{mM}$
3: $1 \mathrm{mM}$

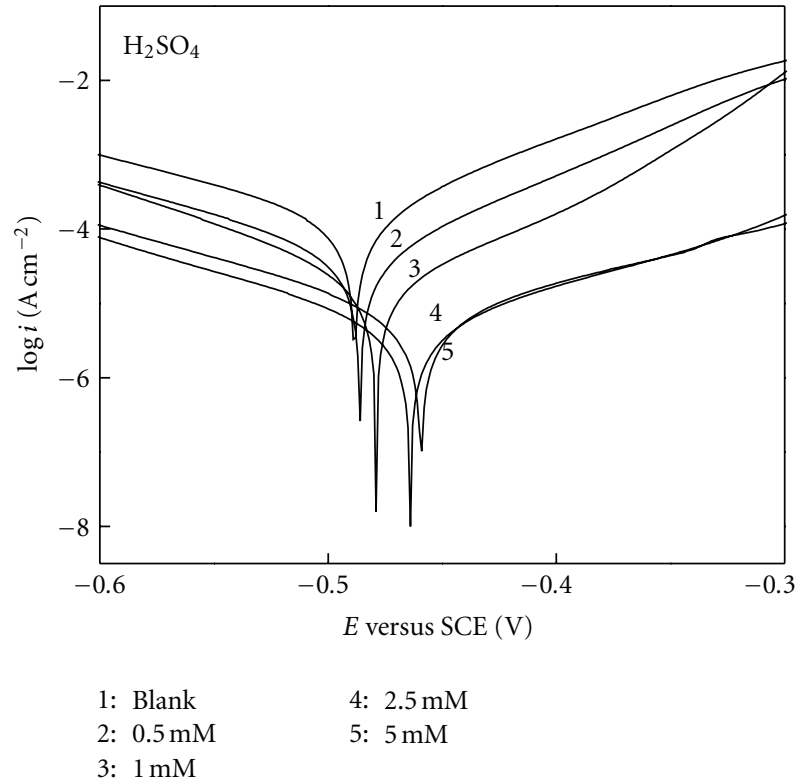

(b)

FIgure 4: Tafel plots for steel in $1.0 \mathrm{M} \mathrm{HCl}$ and $0.5 \mathrm{M} \mathrm{H}_{2} \mathrm{SO}_{4}$ containing different concentration of Lamotrigine, at $30^{\circ} \mathrm{C}$.

circuit model was proposed to fit and analyze EIS data (Figure 6) [10]. EIS parameters calculated in accordance with equivalent circuit are listed in Table 2. Popova et al. [26] said that sum of charge transfer resistance $\left(R_{\mathrm{ct}}\right)$ and adsorption resistance $\left(R_{\mathrm{ad}}\right)$ is equivalent to polarisation resistance $\left(R_{p}\right)$. Inhibition efficiency $\left(\% \eta_{z}\right)$ was calculated using following equation:

$$
\% \eta_{z}=\frac{R_{p}-R_{p}^{\circ}}{R_{p}} \times 100
$$

where $R_{p}$ and $R_{p}^{\circ}$ are polarisation resistance values in presence and absence of inhibitor. Table 2 revealed that $R_{p}$ values increased and capacitance values decreased with inhibitor concentration for both the acids. Decrease in capacitance, which can result from a decrease in local dielectric constant and/or an increase in the thickness of electrical double layer, suggests that the inhibitor molecules act by adsorption at metal/solution interface [27]. This indicated the formation of a surface film on steel. Obtained $\% \eta_{z}$ are in good agreement with $\% \eta_{p}$ and $\% \eta_{w}$. 


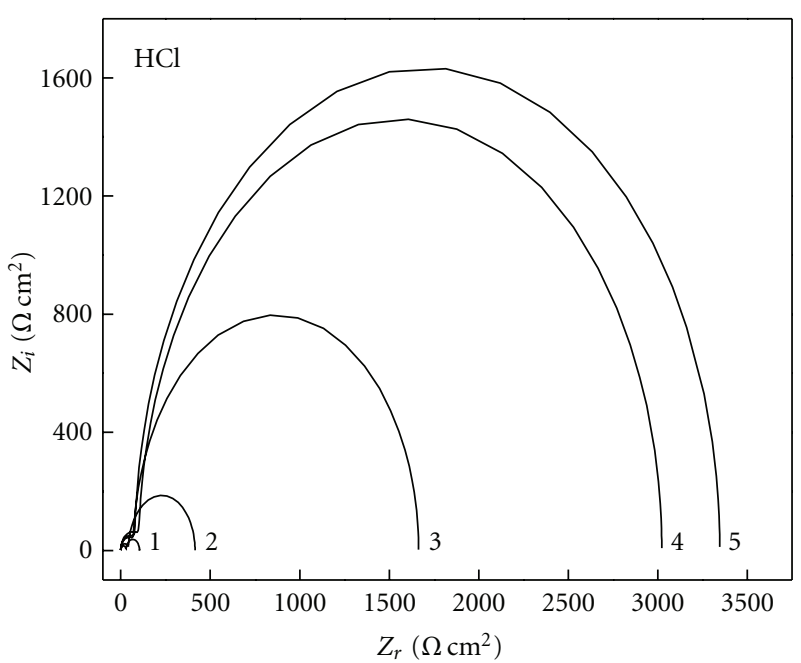

$\begin{array}{ll}\text { 1: } B \text { lank } & 4: 2.5 \mathrm{mM} \\ \text { 2: } 0.5 \mathrm{mM} & \text { 5: } 5 \mathrm{mM} \\ \text { 3: } 1 \mathrm{mM} & \end{array}$

(a)

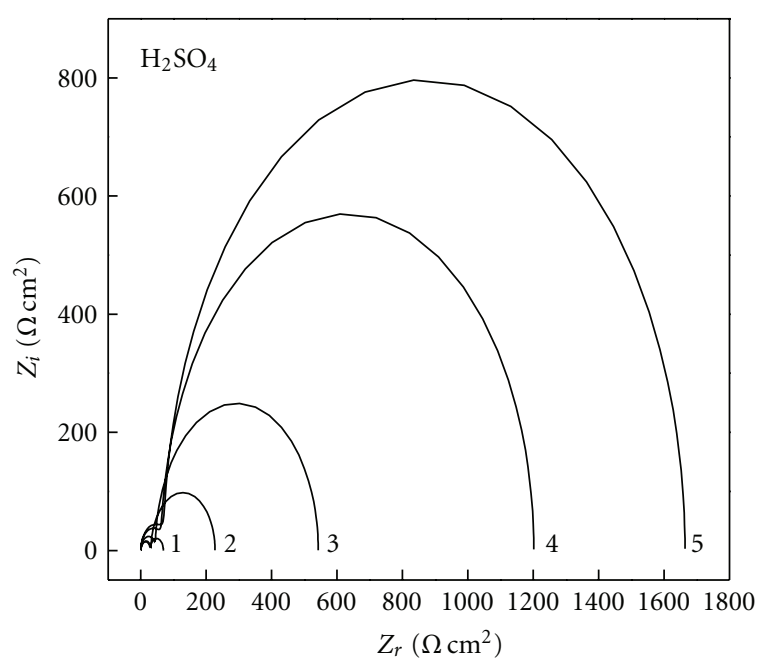

$\begin{array}{ll}\text { 1: } B l a n k & 4: 2.5 \mathrm{mM} \\ \text { 2: } 0.5 \mathrm{mM} & \text { 5: } 5 \mathrm{mM} \\ \text { 3: } 1 \mathrm{mM} & \end{array}$

(b)

Figure 5: Nyquist plot for steel in $1.0 \mathrm{M} \mathrm{HCl}$ and $0.5 \mathrm{M} \mathrm{H}_{2} \mathrm{SO}_{4}$ in presence of different concentrations of lamotrigine inhibitor at $30^{\circ} \mathrm{C}$.

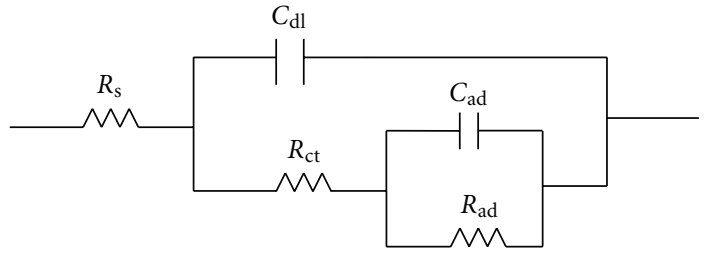

FIGURE 6: Equivalent circuit used to interpret the results of EIS.

3.4. Surface Morphology Study. SEM images were referred to check the protection of steel surface by inhibitor. SEM images of steel plate immersed in $1.0 \mathrm{M} \mathrm{HCl}$ and $0.5 \mathrm{M} \mathrm{H}_{2} \mathrm{SO}_{4}$ in absence and presence of $2.5 \mathrm{mM}$ concentration of lamotrigine, at $30^{\circ} \mathrm{C}$, are given in Figure 7. SEM image of steel in $1.0 \mathrm{M} \mathrm{HCl}$ or $0.5 \mathrm{M} \mathrm{H}_{2} \mathrm{SO}_{4}$ exhibit rough surface with innumerable number of pits, voids, and channels and has an etched surface of various indentation depths. These are essentially due to washing away of soluble corrosion products from metal surface. Whitish/gray spots seen at few locations are corrosion products. This reveals the severity of corrosion caused by $1.0 \mathrm{M} \mathrm{HCl}$ and $0.5 \mathrm{M} \mathrm{H}_{2} \mathrm{SO}_{4}$. SEM image of steel in $\mathrm{H}_{2} \mathrm{SO}_{4}$ protected from lamotrigine shows better surface conditions with few imperfections of smaller depth with no white spots. SEM image of steel in $\mathrm{HCl}$ protected from lamotrigine was least corroded and has retained smooth and glassy surface. Better surface conditions stands in the order $\mathrm{HCl}>\mathrm{H}_{2} \mathrm{SO}_{4}$.

3.5. Adsorption Isotherm. Adsorption isotherms give enough information about the interaction of inhibitor molecules with steel. Surface coverage $(\theta)$ defined as $\% \eta_{w} / 100$ (Table 1) was tested by fitting to various adsorption isotherms like
Langmuir, Temkin, Freundlich and Flory-Huggins. However, the best fit was obtained with Langmuir isotherm. According to Langmuir's isotherm, surface coverage is related to inhibitor concentration $(C)$ by the following equation [28]:

$$
\frac{C}{\theta}=\frac{1}{K_{\mathrm{ads}}}+C
$$

where $K_{\text {ads }}$ is equilibrium constant for adsorption process. The plot of $C / \theta$ versus $C$ yields a straight line (shown in Figure 8) with regression coefficient close to 1 suggests that adsorption obeys Langmuir isotherm. The $K_{\text {ads }}$ values can be calculated from line intercept on $C / \theta$ axis and is related to standard free energy change of adsorption $\left(\Delta G_{\text {ads }}^{\circ}\right)$ as follows [29]:

$$
\Delta G_{\mathrm{ads}}^{\circ}=-2.30 R T \log \left(55.5 K_{\mathrm{ads}}\right),
$$

where $R$ is molar gas constant $\left(8.314 \mathrm{~J} \mathrm{~K}^{-1} \mathrm{~mol}^{-1}\right), T$ is absolute temperature $(\mathrm{K})$, and value 55.5 is concentration of water in mol dm${ }^{-3}$ in solution. Obtained $K_{\mathrm{ads}}$ and $\Delta G_{\text {ads }}^{\circ}$ values are listed in Table 3 . The negative $\Delta G_{\text {ads }}^{\circ}$ and high $K_{\text {ads }}$ value ensures spontaneity of adsorption, stability of the adsorbed film and hence better inhibition efficiency [30]. In our study, negative $\Delta G_{\text {ads }}^{\circ}$ and high $K_{\text {ads }}$ values stood in the order $\mathrm{HCl}>\mathrm{H}_{2} \mathrm{SO}_{4}$, meaning Ziprasidone is more efficient in HCl. $\Delta G_{\text {ads }}^{\circ}$ value of $-20 \mathrm{~kJ} \mathrm{~mol}^{-1}$ or lower indicates electrostatic interaction (physisorption), while those around $-40 \mathrm{~kJ} \mathrm{~mol}^{-1}$ or higher are generally accepted to form a coordinate type of bond (chemisorption) [31]. In our study, value of $\Delta G_{\text {ads }}^{\circ}$ is around $-33 \mathrm{~kJ} \mathrm{~mol}^{-1}$, for both $\mathrm{HCl}$ and $\mathrm{H}_{2} \mathrm{SO}_{4}$, which is an intermediate, indicates that adsorption involves mixture of physisorption and chemisorption. 


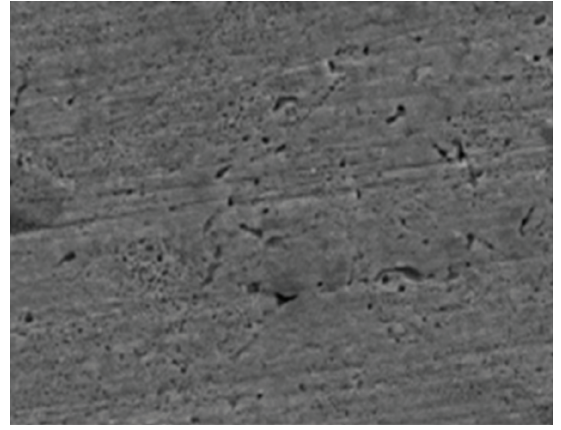

(a)

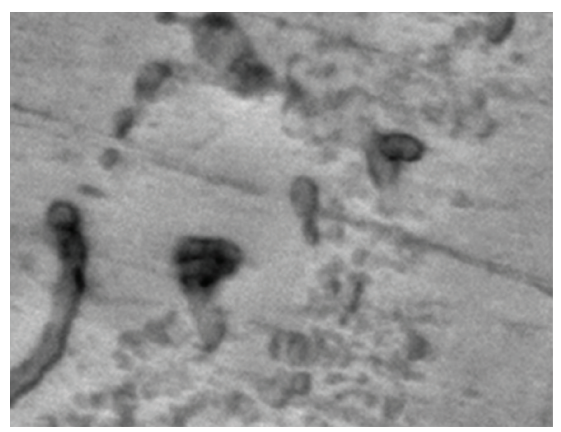

(c)

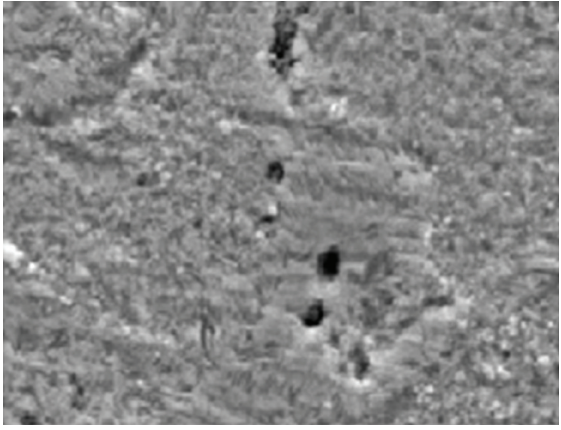

(b)

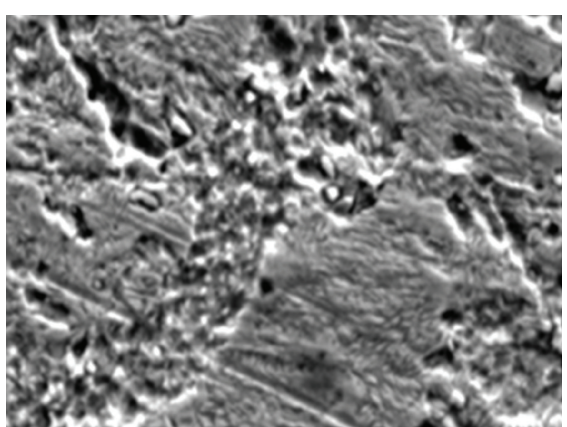

(d)

Figure 7: SEM visuals of steel in $1.0 \mathrm{M} \mathrm{HCl}$ and $0.5 \mathrm{M} \mathrm{H}_{2} \mathrm{SO}_{4}$ in absence and presence of $2.5 \mathrm{mM}$ lamotrigine. (a) Absence of inhibitor in $1.0 \mathrm{M} \mathrm{HCl}$, (b) $0.5 \mathrm{M} \mathrm{H}_{2} \mathrm{SO}_{4}$, (c) $2.5 \mathrm{mM}$ lamotrigine in $\mathrm{HCl}$, and (d) $2.5 \mathrm{mM}$ lamotrigine in $\mathrm{H}_{2} \mathrm{SO}_{4}$.

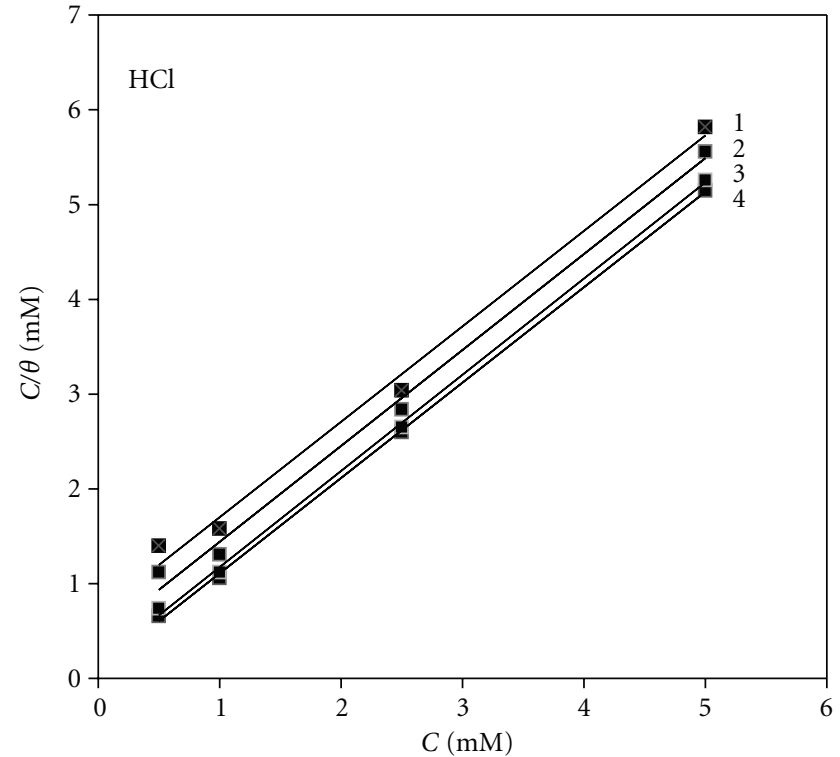
1: $60^{\circ} \mathrm{C}$
3: $40^{\circ} \mathrm{C}$
2: $50^{\circ} \mathrm{C}$

(a)

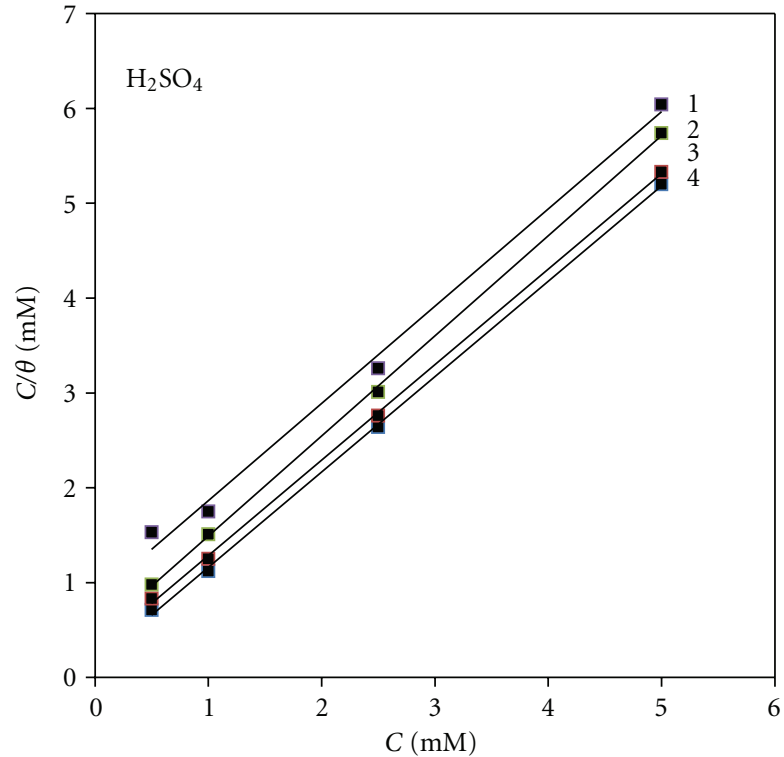
1: $60^{\circ} \mathrm{C}$
3: $40^{\circ} \mathrm{C}$
2: $50^{\circ} \mathrm{C}$
4: $30^{\circ} \mathrm{C}$

(b)

FIGURE 8: Langmuir isotherm for the adsorption of lamotrigine on steel in $1.0 \mathrm{M} \mathrm{HCl}$ and $0.5 \mathrm{M} \mathrm{H}_{2} \mathrm{SO}_{4}$. 
TABLE 3: Adsorption parameters for the adsorption of lamotrigine on steel in $1.0 \mathrm{M} \mathrm{HCl}$ and $0.5 \mathrm{M} \mathrm{H}_{2} \mathrm{SO}_{4}$ solutions at different temperature.

\begin{tabular}{lccc}
\hline $\begin{array}{l}\text { Corrosive } \\
\text { media }\end{array}$ & $\begin{array}{c}\text { Temperature } \\
\left({ }^{\circ} \mathrm{C}\right)\end{array}$ & $K_{\mathrm{ads}}\left(\times 10^{3}\right)$ & $\begin{array}{c}\Delta G_{\mathrm{ads}}^{\circ} \\
\left(\mathrm{k} \mathrm{mol}^{-1}\right)\end{array}$ \\
\hline \multirow{3}{*}{$\mathrm{HCl}$} & 30 & 9.8 & -33.2 \\
& 40 & 6.2 & -32.9 \\
& 50 & 2.3 & -31.6 \\
& 60 & 1.4 & -31.2 \\
\hline $\mathrm{H}_{2} \mathrm{SO}_{4}$ & 30 & 6.4 & -32.1 \\
& 40 & 3.6 & -31.7 \\
& 50 & 2.3 & -31.5 \\
& 60 & 1.1 & -30.7 \\
\hline
\end{tabular}

\section{Conclusion}

(i) Lamotrigine is an effective inhibitor both in $\mathrm{HCl}$ and $\mathrm{H}_{2} \mathrm{SO}_{4}$ but stands slightly better in $\mathrm{HCl}$. This was explicitly supported by all methods employed in the present study.

(ii) Inhibition efficiency increased with concentration and decreased with temperature

(iii) Lamotrigine is a mixed type inhibitor.

(iv) Adsorption and thermodynamic study showed mixture of chemisorption and physisorption of inhibitor.

\section{Acknowledgments}

The authors are grateful to the authorities of Department of Chemistry, Kuvempu University, Karnataka, India for providing lab facilities. The authors also thank Department of Science and Technology, Government of India, New Delhi, (DST: Project Sanction no. 100/IFD/1924/2008-2009 dated 2.07.2008) for providing instrumental facilities.

\section{References}

[1] L. R. Chauhan and G. Gunasekaran, "Corrosion inhibition of mild steel by plant extract in dilute $\mathrm{HCl}$ medium," Corrosion Science, vol. 49, no. 3, pp. 1143-1161, 2007.

[2] K. F. Khaled, "Application of electrochemical frequency modulation for monitoring corrosion and corrosion inhibition of iron by some indole derivatives in molar hydrochloric acid," Materials Chemistry and Physics, vol. 112, no. 1, pp. 290-300, 2008.

[3] M. K. Pavithra, T. V. Venkatesha, K. Vathsala, and K. O. Nayana, "Synergistic effect of halide ions on improving corrosion inhibition behaviour of benzisothiozole-3-piperizine hydrochloride on mild steel in $0.5 \mathrm{M} \mathrm{H}_{2} \mathrm{SO}_{4}$ medium," Corrosion Science, vol. 52, no. 11, pp. 3811-3819, 2010.

[4] I. Ahamad, R. Prasad, and M. A. Quraishi, "Adsorption and inhibitive properties of some new Mannich bases of Isatin derivatives on corrosion of mild steel in acidic media," Corrosion Science, vol. 52, no. 4, pp. 1472-1481, 2010.
[5] O. Benali, L. Larabi, M. Traisnel, L. Gengembre, and Y. Harek, "Electrochemical, theoretical and XPS studies of 2-mercapto1-methylimidazole adsorption on carbon steel in $1 \mathrm{M} \mathrm{HClO}_{4}$," Applied Surface Science, vol. 253, no. 14, pp. 6130-6139, 2007.

[6] Y. Abboud, A. Abourriche, T. Saffaj et al., "2,3-Quinoxalinedione as a novel corrosion inhibitor for mild steel in $1 \mathrm{M} \mathrm{HCl,"}$ Materials Chemistry and Physics, vol. 105, no. 1, pp. 1-5, 2007.

[7] A. K. Singh and M. A. Quraishi, "The effect of some bisthiadiazole derivatives on the corrosion of mild steel in hydrochloric acid," Corrosion Science, vol. 52, no. 4, pp. 13731385, 2010.

[8] G. E. Badr, "The role of some thiosemicarbazide derivatives as corrosion inhibitors for C-steel in acidic media," Corrosion Science, vol. 51, no. 11, pp. 2529-2536, 2009.

[9] J. Aljourani, M. A. Golozar, and K. Raeissi, "The inhibition of carbon steel corrosion in hydrochloric and sulfuric acid media using some benzimidazole derivatives," Materials Chemistry and Physics, vol. 121, no. 1-2, pp. 320-325, 2010.

[10] Y. Yan, W. Li, L. Cai, and B. Hou, "Electrochemical and quantum chemical study of purines as corrosion inhibitors for mild steel in $1 \mathrm{M} \mathrm{HCl}$ solution," Electrochimica Acta, vol. 53, no. 20, pp. 5953-5960, 2008.

[11] A. Popova, E. Sokolova, S. Raicheva, and M. Christov, "AC and DC study of the temperature effect on mild steel corrosion in acid media in the presence of benzimidazole derivatives," Corrosion Science, vol. 45, no. 1, pp. 33-58, 2003.

[12] G. Schmitt, "Application of inhibitors for acid media," British Corrosion Journal, vol. 19, no. 4, pp. 165-176, 1984.

[13] Y. Tang, X. Yang, W. Yang, R. Wan, Y. Chen, and X. Yin, "A preliminary investigation of corrosion inhibition of mild steel in $0.5 \mathrm{M} \mathrm{H}_{2} \mathrm{SO}_{4}$ by 2-amino-5-(n-pyridyl)-1,3,4-thiadiazole: polarization, EIS and molecular dynamics simulations," Corrosion Science, vol. 52, no. 5, pp. 1801-1808, 2010.

[14] E. E. Oguzie, Y. Li, and F. H. Wang, "Corrosion inhibition and adsorption behavior of methionine on mild steel in sulfuric acid and synergistic effect of iodide ion," Journal of Collid and Interface Science, vol. 310, no. 1, pp. 90-98, 2007.

[15] I. Ahamad and M. A. Quraishi, "Bis (benzimidazol-2-yl) disulphide: an efficient water soluble inhibitor for corrosion of mild steel in acid media," Corrosion Science, vol. 51, no. 9, pp. 2006-2013, 2009.

[16] J. H. Henríquez-Romána, L. Padilla-Campos, M. A. P. Páeza et al., "The influence of aniline and its derivatives on the corrosion behaviour of copper in acid solution: a theoretical approach," Journal of Molecular Structure: THEOCHEM, vol. 757, no. 1-3, pp. 1-10, 2005.

[17] J. H. Henrrnquez-Roman, M. Sancy, M. A. Paez et al., "The influence of aniline and its derivatives on the corrosion behaviour of copper in acid solution," Journal of Solid State Electrochemistry, vol. 9, no. 7, pp. 504-511, 2005.

[18] A. K. Singh and M. A. Quraishi, "The effect of some bisthiadiazole derivatives on the corrosion of mild steel in hydrochloric acid," Corrosion Science, vol. 52, no. 4, pp. 13731385, 2010.

[19] R. V. Saliyan and A. V. Adhikari, "Corrosion inhibition of mild steel in acid media by quinolinyl thiopropano hydrazone," Indian Journal of Chemical Technology, vol. 16, no. 2, pp. 162174, 2009.

[20] http://www.drugbank.com/.

[21] A. K. Singh and M. A. Quraishi, "Effect of Cefazolin on the corrosion of mild steel in $\mathrm{HCl}$ solution," Corrosion Science, vol. 52, no. 1, pp. 152-160, 2010. 
[22] S. E. Nataraja, T. V. Venkatesha, and H. C. Tandon, "Computational and experimental evaluation of the acid corrosion inhibition of steel by tacrine," Corrosion Science, vol. 60, pp. 214-223, 2012.

[23] E. E. Ebenso, "Inhibition of aluminium (AA3105) Corrosion in $\mathrm{HCl}$ by acetamide and thiourea," Nigerian Corrosion Journal, vol. 1, no. 1, pp. 29-44, 1998.

[24] E. S. Ferreira, C. Giancomelli, F. C. Giacomelli, and A. Spinelli, "Evaluation of the inhibitor effect of l-ascorbic acid on the corrosion of mild steel," Materials Chemistry and Physics, vol. 83, no. 1, pp. 129-134, 2004.

[25] A. V. Shanbhag, T. V. Venkatesha, R. A. Prabhu, R. G. Kalkhambkar, and G. M. Kulkarni, "Corrosion inhibition of mild steel in acidic medium using hydrazide derivatives," Journal of Applied Electrochemistry, vol. 38, no. 3, pp. 279-287, 2008.

[26] A. Popova, S. Raicheva, E. Sokolova, and M. Christov, "Frequency dispersion of the interfacial impedance at mild steel corrosion in acid media in the presence of benzimidazole derivatives," Langmuir, vol. 12, no. 8, pp. 2083-2089, 1996.

[27] R. A. Prabhu, T. V. Venkatesha, A. V. Shanbhag, G. M. Kulkarni, and R. G. Kalkhambkar, "Inhibition effects of some Schiff's bases on the corrosion of mild steel in hydrochloric acid solution," Corrosion Science, vol. 50, no. 12, pp. 33563362, 2008.

[28] F. Bentiss, M. Lebrini, and M. Lagrenée, "Thermodynamic characterization of metal dissolution and inhibitor adsorption processes in mild steel/2,5-bis(n-thienyl)-1,3,4-thiadiazoles/ hydrochloric acid system," Corrosion Science, vol. 47, no. 12, pp. 2915-2931, 2005.

[29] E. Machnikova, K. H. Whitmire, and N. Hackerman, "Corrosion inhibition of carbon steel in hydrochloric acid by furan derivatives," Electrochimica Acta, vol. 53, no. 20, pp. 6024 6032, 2008.

[30] R. Solmaz, G. Kardas, B. Yazıc1, and M. Erbil, "Adsorption and corrosion inhibitive properties of 2-amino-5-mercapto-1,3,4thiadiazole on mild steel in hydrochloric acid media," Colloids and Surfaces A, vol. 312, no. 1, pp. 7-17, 2008.

[31] O. Benali, L. Larabi, M. Traisnel, L. Gengembre, and Y. Harek, "Electrochemical, theoretical and XPS studies of 2-mercapto1-methylimidazole adsorption on carbon steel in $1 \mathrm{M} \mathrm{HClO}_{4}$," Applied Surface Science, vol. 253, no. 14, pp. 6130-6139, 2007. 

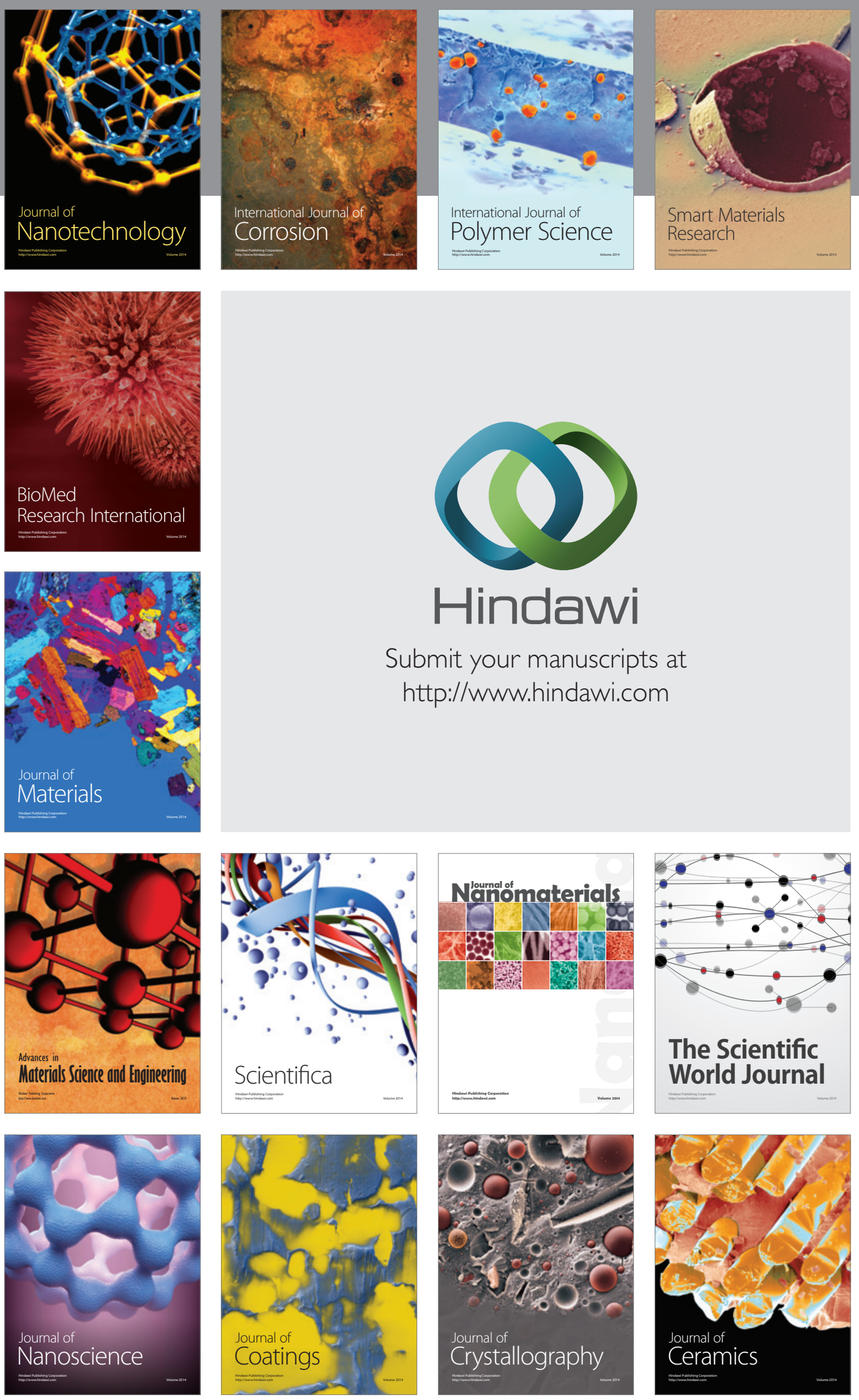

The Scientific World Journal

Submit your manuscripts at

http://www.hindawi.com

\section{World Journal}

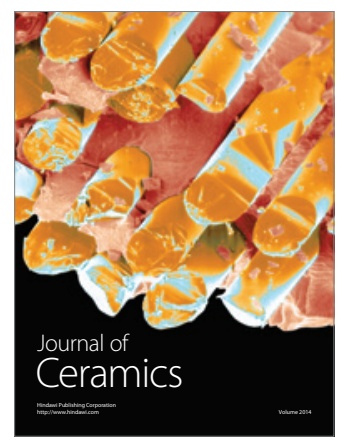

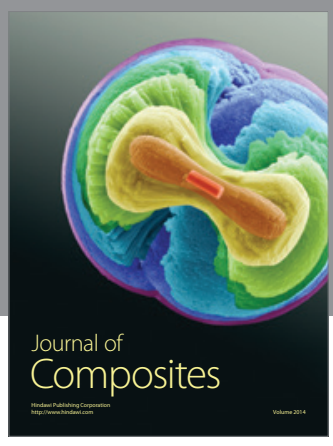
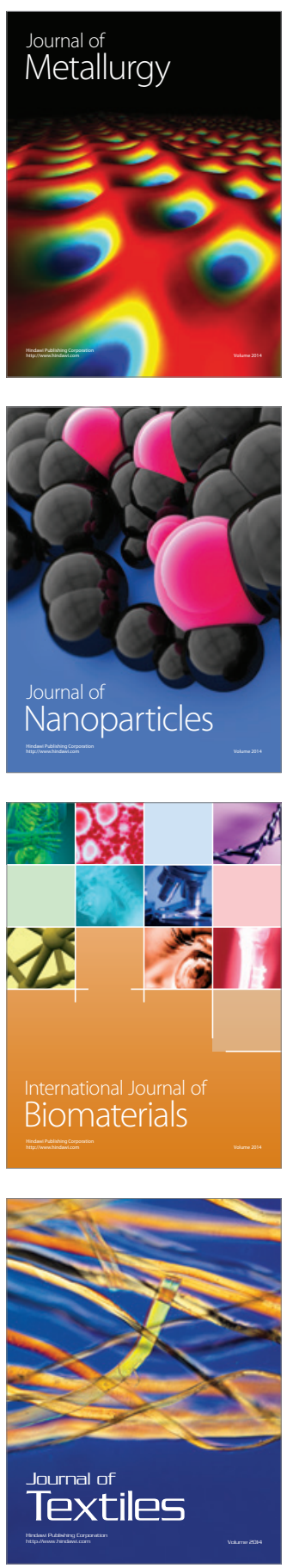